\title{
Synthesis of Graphene Nanoribbons-Hydroxyapatite Nanocomposite Applicable in Biomedicine and Theranostics
}

\author{
Hassan Nosrati ${ }^{1}\left(\mathbb{D}\right.$, Rasoul Sarraf-Mamoory ${ }^{1, * \mathbb{C}}$, Amir Hossein Ahmadi ${ }^{2} \mathbb{D}$ and \\ Maria Canillas Perez ${ }^{3}$ \\ 1 Department of Materials Engineering, TarbiatModares University, Tehran P.O. Box 14115-111, Iran \\ 2 Department of Basic Science, Shahed University, Tehran P.O. Box 18155/159, Iran \\ 3 Instituto de Cerámica y Vidrio, CSIC, 28006 Madrid, Spain \\ * Correspondence: rsarrafm@modares.ac.ir
}

Academic Editors: Dong-Wook Han and Ajeet Kaushik

Received: 12 February 2020; Accepted: 17 April 2020; Published: 22 April 2020

\begin{abstract}
In order to investigate the effect of graphene nanoribbons on the final properties of hydroxyapatite-based nanocomposites, a solvothermal method was used at $180{ }^{\circ} \mathrm{C}$ and $5 \mathrm{~h}$ for the synthesis of graphene nanoribbons-hydroxyapatite nanopowders by employing hydrogen gas injection. Calcium nitrate tetrahydrate and diammonium hydrogenphosphate were used as calcium and phosphate precursors, respectively. To synthesize the powders, a solvent containing diethylene glycol, anhydrous ethanol, dimethylformamide, and water was used. Graphene oxide nanoribbons were synthesized by chemical unzipping of carbon nanotubes under oxidative conditions. The synthesized powders were consolidated by spark plasma sintering methodat $950{ }^{\circ} \mathrm{C}$ and a pressure of $50 \mathrm{MPa}$. The powders and sintered samples were then evaluated using X-ray diffraction, Raman spectroscopy, high-resolution transmission electron microscopy, Vickers microindentation techniques, and biocompatibility assay. The findings of this study showed that the final powders synthesized by the solvothermal method had calcium to phosphate ratio of about 1.67. By adding a small amount of graphene nanoribbon $(0.5 \% \mathrm{~W})$, elastic modulus and hardness of hydroxyapatite increased dramatically. In biological experiments, the difference of hydroxyapatite effect in comparison with the nanocomposite was not significant. The findings of this study showed that graphene nanoribbons have a positive effect on the properties of hydroxyapatite, and these findings would be useful for the medical and theranostic application of this type of nanocomposites.
\end{abstract}

Keywords: hydroxyapatite; solvothermal; graphene nanoribbons; theranostic

\section{Introduction}

Hydroxyapatite (HA, a member of the calcium phosphate family) has poor mechanical properties. The most important of these properties are low fracture toughness (fracture toughness of less than $1 \mathrm{MPa} \cdot \mathrm{m}^{0.5}$ ), intrinsic brittleness, poor tensile strength, and weak wear resistance [1-4]. However, despite these poor mechanical properties, HA has excellent biological properties, including bone bonding ability, excellent biocompatibility, highly compatible with living bone tissues, scaffolding properties, and osteoconductive properties [5-10]. These properties have made HA widely used in biomedical applications. Therefore, many methods have been employed to synthesize this bioceramic, such as combustion preparation, electrochemical deposition, hydrolysis, precipitation, sputtering, multiple emulsion, solid-state reaction, biomimetic deposition, solvothermal method, sol-gel, and hydrothermal process [11-23], which have led to diverse morphologies such as ribbons, rods, wires, and tubes [24-29]. However, to eliminate mechanical weaknesses, researchers have used different 
reinforcing materials. Among the materials used, carbon nanomaterials such as carbon nanotubes (CNTs), graphene, graphene oxide, and graphene nanoribbons (GNRs) have received more attention than others [30-32]. The most important reason is the biocompatibility and high mechanical properties of these materials. Graphene with honeycomb structure, excellent mechanical properties, and high specific surface area has been studied more than carbon nanotubes [33-38].

The results of investigations showed that the addition of graphene sheets to HA greatly improved its mechanical and biological properties $[39,40]$. However, the excessive addition of graphene sheets has reduced the mechanical properties, because graphene sheets fold up and prevent high relative densities [41]. One way to control this weakness is to use GNRs instead of graphene sheets. GNRs have been used in some research to enhance the properties of HA. GNRs are synthesized in various ways. One of these methods is the use of carbon nanotubes. Unzipping CNTs create GNRs [42]. However, for the use of carbon nanomaterials as a reinforcement phase, the surface of these materials must contain chemical agents, such as graphene oxide surface. Published research has also used materials such as graphene oxide. Graphene oxide is reduced by methods such as the hydrothermal process, and its mechanical properties are improved $[43,44]$. Unzipping the CNTs chemically also makes graphene oxide nanoribbons (GONRs) [42].

One of the best methods for the synthesis of hybrid powders containing HA is hydrothermal (solvothermal) process. In this method, the precursor containing the calcium ions is first added to the solution containing carbon nanomaterials. The solution containing phosphate ions is then added to the previous solution. In this way, calcium phosphate powders precipitate as white powders. These powders are then transferred to a hydrothermal autoclave and the process is performed. During the hydrothermal process, these primary powders dissolve at high temperatures and begin nucleation and growth of HA. Nucleation of HA crystals is formed on the surface agents of carbon nanomaterials by van der Waals forces $[40,43,44]$. In some published studies, ultrasound operations have been used to reduce the particles size of the synthesized HA [45]. For hydrothermal process, reducing the size of the initial powders by ultrasound effects will cause them to dissolve more rapidly in the hydrothermal process, increasing the reaction kinetics and enhancing the quality of the final powders.

Based on the above, in this study, GNRs were used to enhance the mechanical properties of HA. GONRs have been used for this purpose. For the synthesis of hybrid powders, the hydrothermal method under hydrogen gas pressure has been used. To improve the properties of the synthesized powders, ultrasound operations have been used. The synthesized powders were sintered by spark plasma sintering (SPS) method. Synthesized powders and consolidated samples were characterized by various methods, including $\mathrm{X}$-ray diffraction (XRD), Raman spectroscopy, high-resolution transmission electron microscopy (HR-TEM), and Vickers indentation technique. So far, a lot of research has been done on the applications of HA and graphene materials in the field of theranostics, which confirms the capabilities of these materials in this field [46-51]. Given that each phase of the nanocomposite has the potential to be used in biomaterials and theranostics, the synthesized nanocomposite is expected to be usable in biological and theranostic applications.

\section{Materials and Methods}

The primary chemicals used in this study, along with their specifications, are presented in Table 1. The specifications of the CNTs, the materials used in the GONRs synthesis section, and the results obtained are exactly the same as the reference used [42]. The initial solution (S1) was first prepared (DI water + DEG + DMF+ anhydrous ethanol with a volume ratio of 40:20:20:20), and the following steps were performed in order. $4.7 \mathrm{~g}$ of calcium nitrate tetrahydrate in $120 \mathrm{~mL}$ of $\mathrm{S} 1$ was added dropwise to a $20 \mathrm{~mL}$ stirred suspension of GONR $(3.13 \mathrm{mg} / \mathrm{mL})(\mathrm{HA} / 0.5 \% \mathrm{rGONR})$ with stirring continued for 1 h.1.56 g of diammonium hydrogenphosphate in $80 \mathrm{~mL}$ of $\mathrm{S} 1$ was dropwise added to the solution, and the $\mathrm{pH}$ of the resulted solution was adjusted to $>10$ with ammonium solution.The suspension was sonicated for $1 \mathrm{~h}$ (Irradiation power of 140W, A QSONICAQ700 sonicator with a maximum power output of $700 \mathrm{~W}$ was employed for the ultrasonic irradiation).The resulting solution was poured into 
the Teflon (PTFE) vessel and transferred to the autoclave. The solvothermal process was carried out for $5 \mathrm{~h}$ at $180{ }^{\circ} \mathrm{C}$ by injection of hydrogen gas at 10 bar (the volume of the PTFE container was $340 \mathrm{~mL}$ and the total pressure was 23 bar). The powders were dried at oven for $12 \mathrm{~h}$ at $60{ }^{\circ} \mathrm{C}$. After drying and ball milling (250 rpm, $12 \mathrm{~h}$ ), the powders were consolidated via SPS.To compare the effect of reduced GONR on the final properties, a pure HA powders sample was synthesized under similar conditions.

Table 1. The primary chemical used in the powders synthesis phase.

\begin{tabular}{|c|c|c|c|}
\hline Chemical & Company & Purity & Formulation \\
\hline $\begin{array}{l}\text { Graphene oxide nanoribbons } \\
\text { (GONRs) }\end{array}$ & \multicolumn{3}{|c|}{$\begin{array}{c}\text { GONRs were synthesized by chemical unzipping of CNTs under oxidative } \\
\text { condition [42] }\end{array}$} \\
\hline $\begin{array}{c}\text { Calcium nitrate tetrahydrate } \\
\text { Diammonium } \\
\text { Hydrogenphosphate }\end{array}$ & $\begin{array}{l}\text { Merck (Kenilworth, NJ, } \\
\text { USA) }\end{array}$ & $>99 \%$ & $\begin{array}{c}\mathrm{Ca}\left(\mathrm{NO}_{3}\right)_{2} \cdot 4 \mathrm{H}_{2} \mathrm{O} \\
\left(\mathrm{NH}_{4}\right)_{2} \mathrm{HPO}_{4}\end{array}$ \\
\hline Ammonium solution & & $25 \%$ & $\mathrm{NH}_{4} \mathrm{OH}$ \\
\hline $\begin{array}{c}\text { Anhydrous ethanol } \\
\text { Dimethyl formamide (DMF) } \\
\text { Dyethylene glycol (DEG) }\end{array}$ & $\begin{array}{l}\text { Sigma Aldrich (St. Louis, } \\
\text { MO, USA) }\end{array}$ & $>99 \%$ & $\begin{array}{c}\mathrm{CH}_{3} \mathrm{CH}_{2} \mathrm{OH} \\
\left(\mathrm{CH}_{3}\right)_{2} \mathrm{NC}(\mathrm{O}) \mathrm{H} \\
\left(\mathrm{HOCH}_{2} \mathrm{CHc}\right)_{2} \mathrm{O}\end{array}$ \\
\hline
\end{tabular}

\subsection{Evaluation of the Sintered Samples}

As previously reported [52], sintering of the powders was performed at $950^{\circ} \mathrm{C}$. The biocompatibility assays were performed exactly similar to the previous report [52]. The Archimedes method was used to calculate the relative density of sintered samples (ASTM C373-88).

\subsection{Vickers Indentation}

Grindosonic tester with a Vickers tip was conducted on the polished surfaces of samples at a maximum load of $300 \mathrm{mN}$ (ramp dwell time of $10 \mathrm{~s}$ ). Nine tests were performed at different locations of each sample. Elastic modulus and hardness were calculated from the load-displacement curves using Olive-Pharr method [53]. Figure 1 shows load-displacement diagram, load-time, contact depth-time diagrams, indentation affected zone, and contact depth profile for this test. The results were statistically evaluated by the Kernel Density Estimation method [54,55].

\subsection{Characterization Techniques}

Diamond 3.2 and Imagej 1.52d softwares were used in this study. Different evaluation methods have been used in this research, some of which are described below. The other instruments used to characterize the samples include inductively coupled plasma (ICP) (DV7300, Optima Co.), and portable scanning electron microscope (SEM, TM-1000).

\subsubsection{X-Ray Diffraction}

XRDwas used to determine the phase constituents of the samples ( $X^{\prime}$ Pert Pro, Panalytical Co., contained a detector $\mathrm{Cu} \mathrm{K} \alpha$ radiation, $\lambda=1.5406 \AA, 40 \mathrm{kV}, 40 \mathrm{~mA}, 2$ theta scanning range from $10^{\circ}$ up to $80^{\circ}$ in steps of $0.02^{\circ}$ ). Equation (1) was used to estimate the crystallinity of HA (Xc) [56].

$$
x_{c}=1-\frac{v_{(112 / 300)}}{\mathrm{I}_{300}}
$$

where $v_{(112 / 300)}$ and $I_{300}$ are the intensity of the hollow between diffraction peaks of HA in the planes (300) and (112) and the intensity of the peak of HA in the plane (300), respectively. Equation (2) was used to calculate the crystallite size (Williamson-Hall method) [57].

$$
\beta \cos \theta=\frac{0.9 \lambda}{d}+4 \varepsilon \sin \theta
$$


In this equation, $d, \theta$, and $\lambda$ are grain size, Bragg diffraction angle, and wave length of used X-ray $(\mathrm{Cu})$, respectively. $\beta$ and $\varepsilon$ are full width at half height (FWHM), and crystalline lattice strain, respectively.

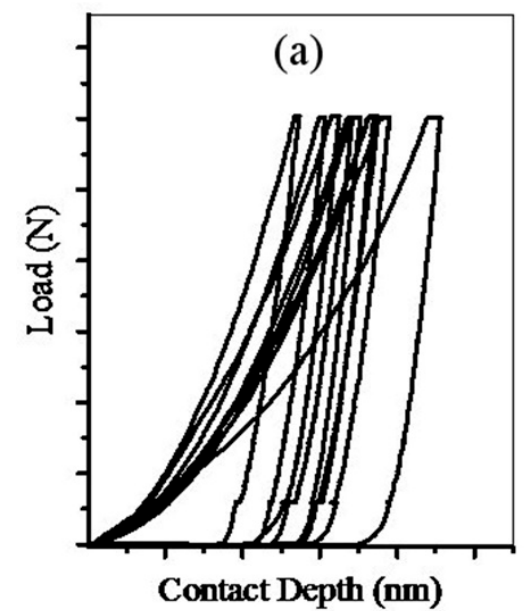

(d)
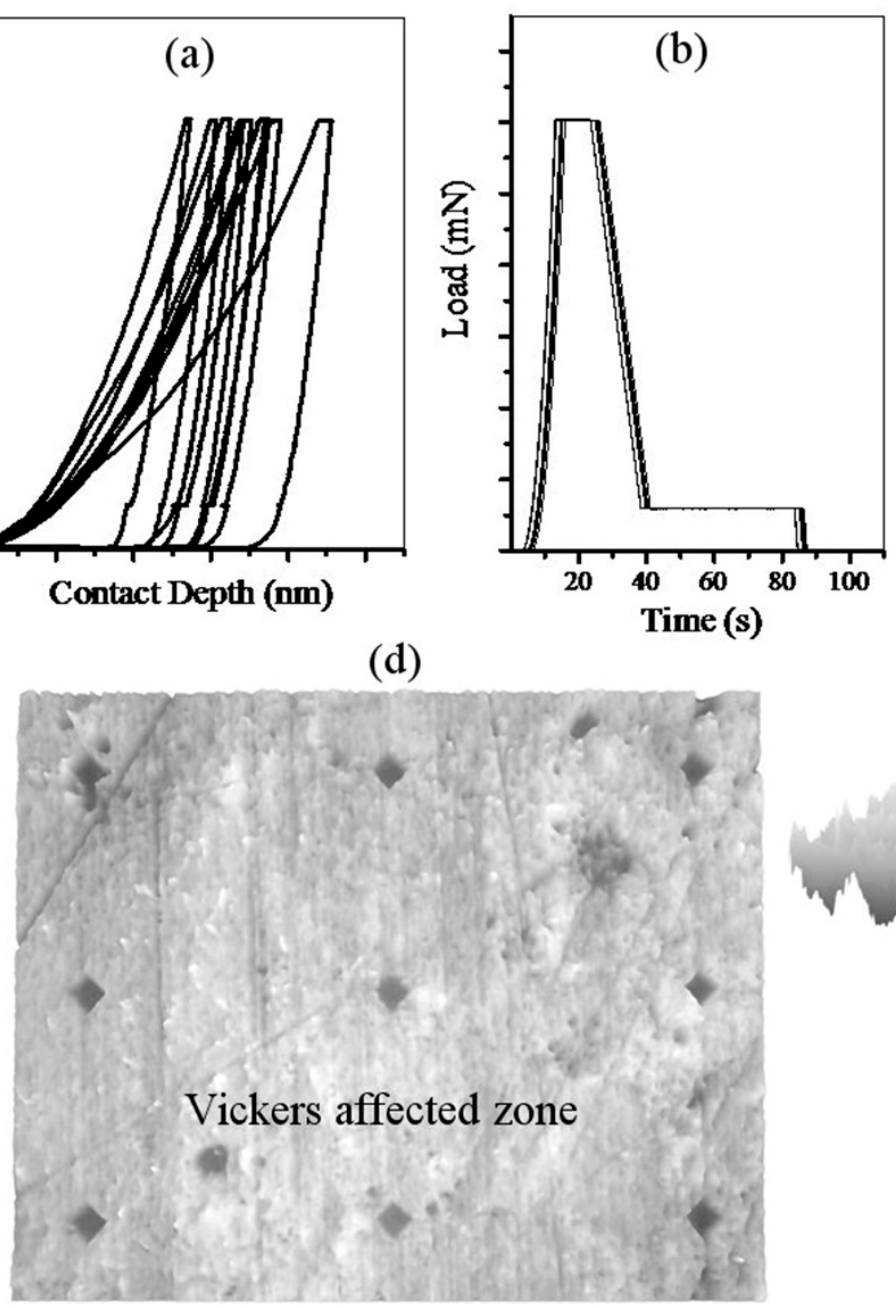

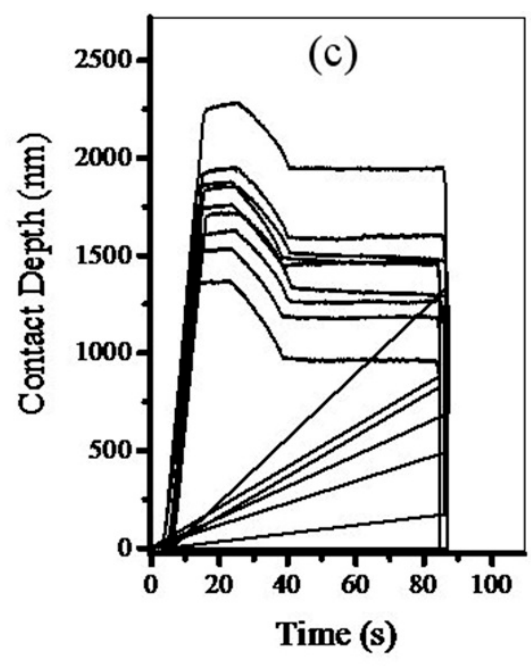

(e)

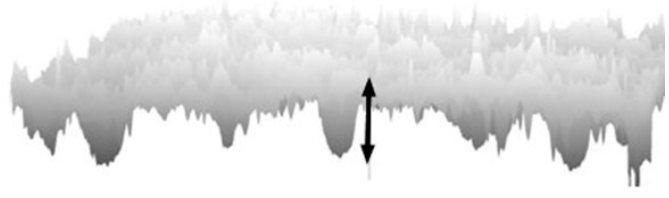

Contact Depth

Figure 1. (a) Load-displacement diagram, (b) load-time diagram, (c) contact depth-time diagram, (d) indentation affected zone, and (e) contact depth profile.

\subsubsection{Field Emission Scanning Electron Microscopy}

FESEM (Hitachi, Düsseldorf, Germany, S4700 equipped with energy dispersive X-ray spectroscopy) was used to observe the morphology of the samples (mounted in an adhesive carbon film and $\mathrm{Au}$ coated by sputtering for its observation).

\subsubsection{Fourier Transform Infrared Spectroscopy}

Fourier transform infrared spectroscopy (FTIR, VERTEX 70, Bruker Corp., Billerica, MA, USA) was used to identify the functional groups of the samples (resolution of $4 \mathrm{~cm}^{-1}$, scan number of 8 , spectral region from 400 to $4000 \mathrm{~cm}^{-1}$ using $2 \mathrm{~cm}^{-1}$ steps). The samples were prepared and mixed with potassium bromide ( $\mathrm{KBr}, 1 \mathrm{mg}$ powdered samples and $300 \mathrm{mg} \mathrm{KBr}$ ). The mixture was pressed into discs by applying $200 \mathrm{MPa}$ pressures (1 mm thickness). The spectra were collected at room conditions (60\% relative humidity). 


\subsubsection{Raman Spectroscopy}

Renishaw inVia (Wotton-under-Edge, UK) spectrometer was used in the range of $300-3500 \mathrm{~cm}^{-1}$, recording five times for $10 \mathrm{~s}$ of each accumulation, with a wavelength of $532 \mathrm{~nm}$, green laser line that had been excited from an argon ion laser in a backscattering configuration using a microscope with a $100 \times$ objective, $100 \%$ power (an acquisition time of $10 \mathrm{~s}$ ). An optical microscope was used with the Raman spectrometer. In order to remove the fluorescence background, the samples were subjected on Al foil.

\subsubsection{High-Resolution Transmission Electron Microscopy}

TALOS F200A with a twin lens system(X-FEG electron source, Ceta 16M camera and a super-X EDS detector) was used to observe atomic structure of the samples and spatially resolved elemental analysis, with a spatial resolution higher than $2 \mathrm{~nm}$. To study the atomic structure, fast fourier transform (FFT) and inverse fast fourier transform (IFFT) analysis were used.

\section{Results and Discussion}

Figure 2 shows the XRD pattern of GNR-HA powders, HA crystal planes, and FESEM images of GNR-HA powders. According to the XRD pattern of the synthesized powders (Figure 2a), full conformity is achieved between the reference standard of pure HA (JCPDS 09-0432) and the peaks obtained [52]. Accordingly, the HA has a high purity hexagonal structure. In other words, the XRD pattern of the GNR-HA powders is quite similar to pure HA. GONR has a peak in the range of $2 \theta=10$ ((001) peak). After reduction of GONR, this peak is removed and a new one ((002) peak) appears around $2 \theta=26$. This peak is much weaker and wider than the HA (002) peak (it is shorter in intensity, and its diffraction angle covers a larger range) due to the amorphous structure of reduced GONR [42,56]. Therefore, this peak is covered by the HA (002) peak, which is highly intensified due to its high crystallinity. Table 2 shows the specification of the HA scatter planes obtained. According to the XRD pattern, $<300>,<211>$, and $<002>$ directions are the main growth directions in HA crystals, where (002) and (300) planes are perpendicular (Figure 2b,c). It is clear that injection of a gas of and thus an increase in total autoclave pressure will increase the crystallinity from to $86 \%$ (Equation (1)) and crystallite size to $28 \mathrm{~nm}$ (Equation (2)). As shown in the FESEM image (Figure 2d), the HA particles have agglomerated in some places. It is clear that morphology of these particles is nanorod-shaped. These nanorods are less than 50 nanometers in diameter. As with similar reports previously published, here is the direction of the growth of nanorods in the C-axis. Additionally, these images confirm the presence of GNRs in the powders. The size of the HA particles is smaller than that of samples synthesized under similar conditions without ultrasound treatment. The reason for this is the use of ultrasound irradiation $[40,43,58,59]$.

Table 2. Specification of the hydroxyapatite (HA) scatter planes in graphene nanoribbon (GNR)-HA powders.

\begin{tabular}{cc}
\hline $\left.\mathbf{2 \theta} \mathbf{(}^{\circ}\right)$ & $\mathbf{( h k l ) , \mathbf { d } - s p a c i n g}(\mathbf{\AA})$ \\
\hline 26 & $(002), 3.43$ \\
32 & $(211), 2.81$ \\
32.3 & $(112), 2.77$ \\
33 & $(300), 2.71$ \\
35.6 & $(202), 2.52$ \\
39.9 & $(310), 2.25$ \\
49.6 & $(213), 1.84$ \\
\hline
\end{tabular}



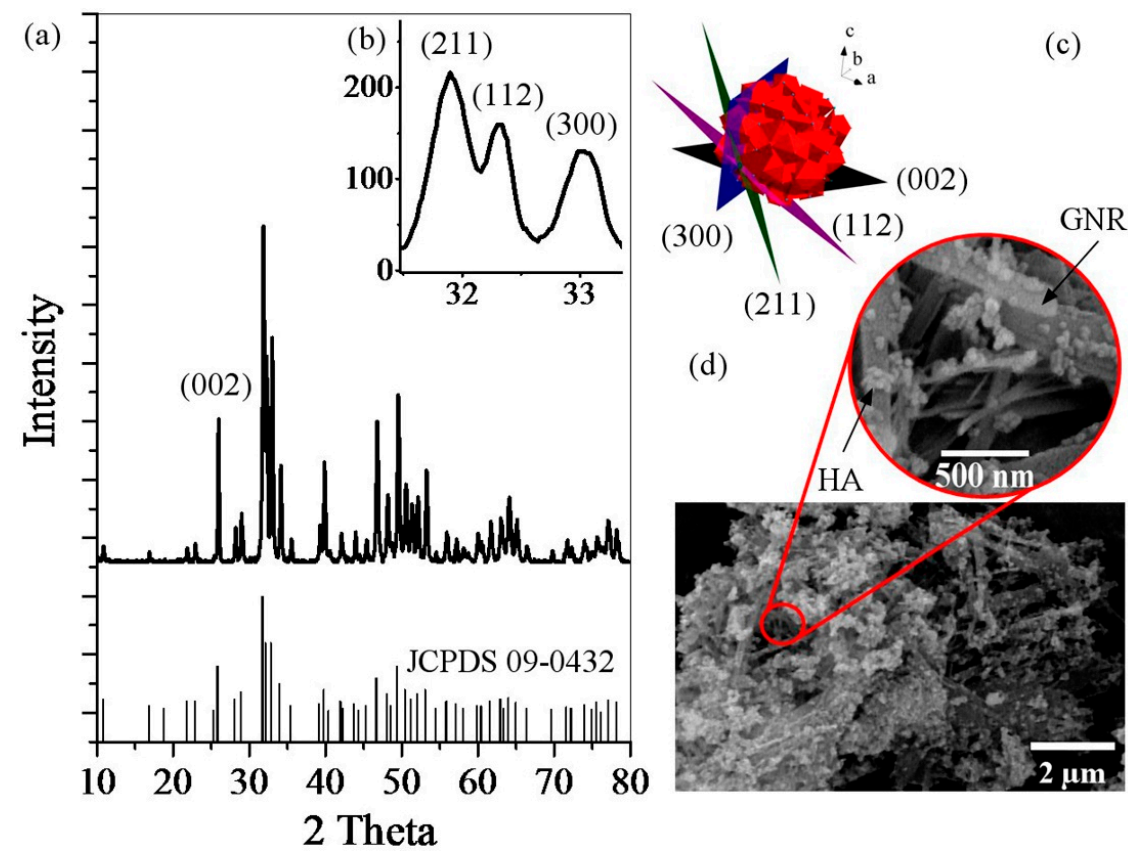

Figure 2. (a,b) XRD pattern of GNR-HA powders synthesized via solvothermal process for $5 \mathrm{~h}$ at $180{ }^{\circ} \mathrm{C}$ by injection of hydrogen gas at 10 bar, (c) HA crystal planes, and (d) FESEM images of GNR-HA powders.

Figure 3 shows the EDS analysis, elemental mapping, FTIR analysis, and Raman spectroscopy for GNR-HA powders. Elemental mapping for synthesized powders confirm the homogeneous distribution of calcium, phosphorous, oxygen, and carbon elements, which is aligned with the EDS analysis. At the end of the solvothermal process, some of the residual solution was controlled by ICP analysis. The amount of elements checked in the ICP analysis were very low and negligible, and the calcium to phosphate ratio in the inputs was about 1.67 and. ICP results and homogeneous element maps confirm the 1.67 ratio of calcium to phosphate for the final product [56]. Figure 5 shows FTIR analysis and Raman spectroscopy for synthesized powders and GO. The peak at $565 \mathrm{~cm}^{-1}$ is related to $\mathrm{P}-\mathrm{O}$ bending in HA. The peaks at 925, 1035, and $1095 \mathrm{~cm}^{-1}$ are related to $\mathrm{P}-\mathrm{O}(\mathrm{H})$ stretching vibration in HA. The peak at $1055 \mathrm{~cm}^{-1}$ is related to $\mathrm{C}-\mathrm{O}$ stretching vibration in GONR. The peak at $1230 \mathrm{~cm}^{-1}$ is related to $\mathrm{C}-\mathrm{OH}$ stretching vibration in GONR. The peak at $1395 \mathrm{~cm}^{-1}$ is related to $\mathrm{C}-\mathrm{O}-\mathrm{H}$ deformation vibration in GONR. The peak at $1620 \mathrm{~cm}^{-1}$ is related to $C=C$ stretching vibration in GONR. The peak at $1730 \mathrm{~cm}^{-1}$ is related to $C=O$ stretching vibration in GONR. The peak at $3400-3500 \mathrm{~cm}^{-1}$ is related to $\mathrm{O}-\mathrm{H}$ stretching vibration in HA and GONR. The FTIR analysis reveals that the synthesized powders contain GNR and HA. By comparing the GONR peaks with the final GNR-HA powders peaks, it is found that the bonds related to the oxygen-containing functional groups on the GONR surface have reduced well and some of the peaks have completely disappeared. The peaks at $1395 \mathrm{~cm}^{-1}$ and $1730 \mathrm{~cm}^{-1}$ are shifted upwards, indicating reduction of GONR, since these two peaks are characteristic of GONR [40-44,60-62].

The Raman spectroscopy has been done to confirm the presence of reduced GONR.v $1, \mathrm{PO}_{4}{ }^{3-}(\mathrm{P}-\mathrm{O})$ is symmetric stretching peaks in HA located at $962 \mathrm{~cm}^{-1}$. D bond is related to the symmetric oscillations of the A1g of carbon atoms with the $\mathrm{SP}^{3}$ hybrid in GNR located at $1350 \mathrm{~cm}^{-1}$. G bond is related to the shaking of the E2g of carbon atoms phonon with the $\mathrm{sp}^{2}$ hybrid in GNR located at $1600 \mathrm{~cm}^{-1}$. 2D peak is related to the number of layers of the GNR located at $2700 \mathrm{~cm}^{-1}$. The rGONR-related Raman signals in this spectrum are much clearer than the HA signal, although its weight percent in the powders is much lower [40-44]. Compared to peaks related to pure HA synthesized in the same way, some displacement is observed in these peaks, which is probably related to the applied gas pressure [63]. 

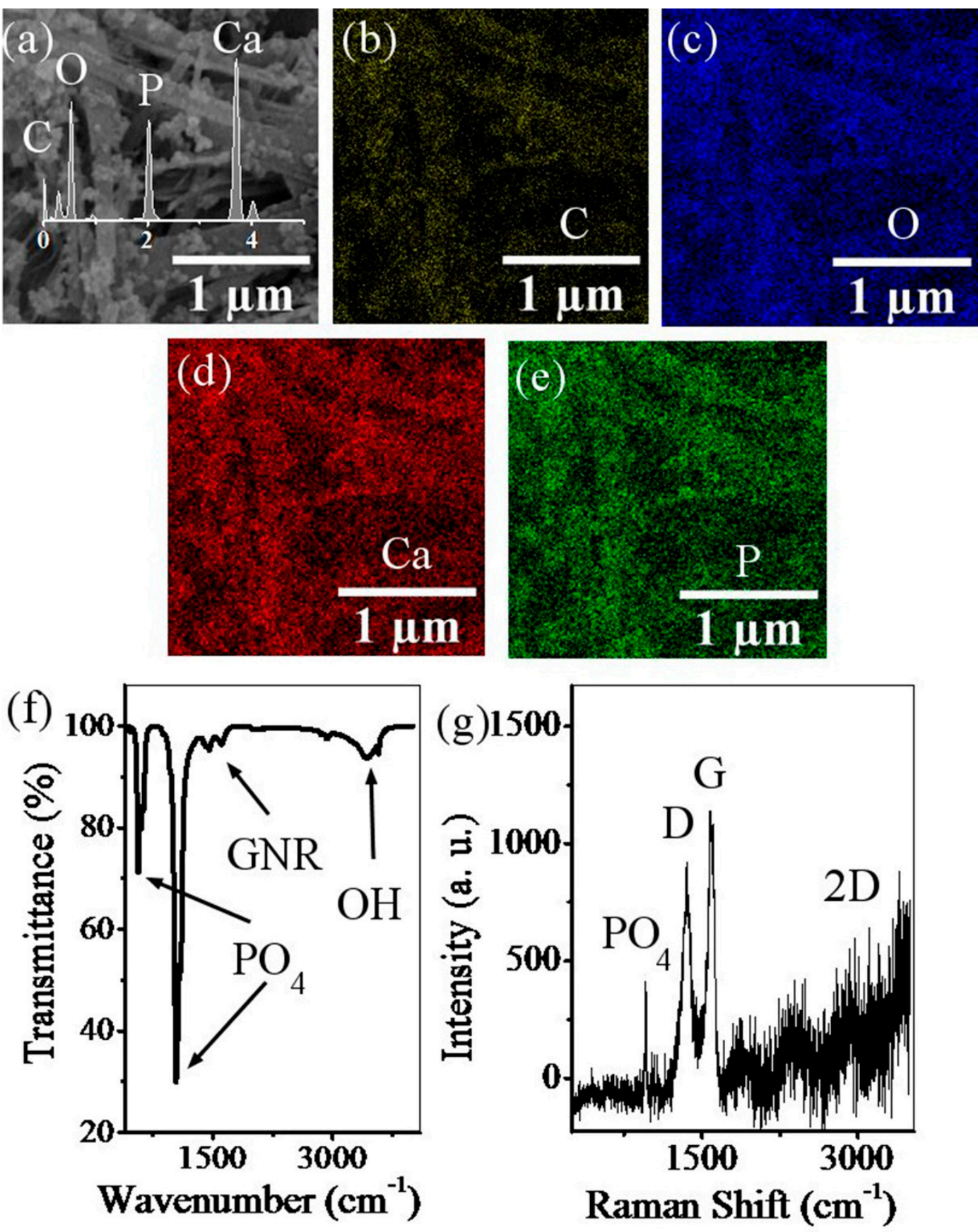

Figure 3. (a) EDS analysis, (b-e) elemental mapping, (f) FTIR analysis, and (g) Raman spectroscopy for GNR-HA powders synthesized via solvothermal process for $5 \mathrm{~h}$ at $180^{\circ} \mathrm{C}$ by injection of hydrogen gas at 10 bar.

Figure 4 illustrates the HRTEM image with the FFT and IFFT analysis of composite powders. Three areas were considered in the HRTEM image (Figure 4a). As the analysis of region A shows (Figure 4c), the (100) planes are marked with the d-spacing. In region B (Figure 4d), the HA particles grow along the (211) planes and show a d-spacing of $0.28 \mathrm{~nm}$. In region C (Figure 4e), the HA particles grow along the (002) planes and show a d-spacing of $0.34 \mathrm{~nm}$. According to the schematic images (Figure $4 \mathrm{~b}$ ), the atomic alignment of the crystalline planes with GNR surface is less than the limit $(0.25)$. Therefore, the interface between the two phases on the GNR surface is likely coherent. According to these findings, (300) planes are likely in contact with the surface of GNR. In this research, during the synthesis of HA, its (300) planes are prior to the (100) planes [41,64]. 


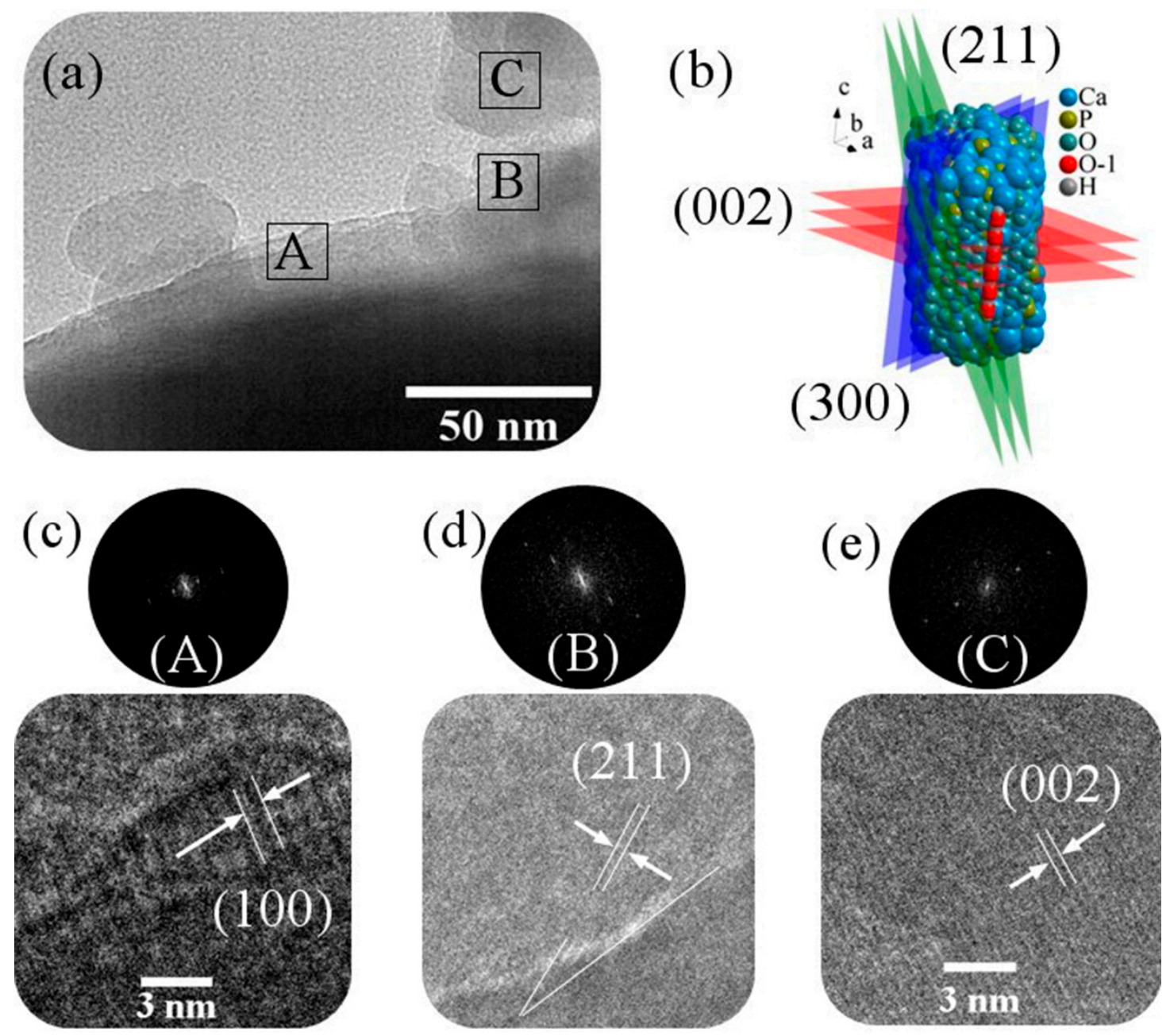

Figure 4. (a) HRTEM image of GNR-HA powders synthesized via solvothermal process for $5 \mathrm{~h}$ at $180^{\circ} \mathrm{C}$ by injection of hydrogen gas at 10 bar; (b) HA nanorods crystal planes; and (c-e) fast fourier transform (FFT) and inverse fast fourier transform (IFFT) analysis of A, B, and C areas (HRTEM), respectively.

Density calculations from the Archimedes method showed that GNR-HA nanocomposite and pure HA reached to relative densities of $97.11 \%$ and $98.3 \%$, respectively. Figure 5 shows the force-displacement diagrams of the sintered samples along with the mechanical properties extracted from these diagrams, FESEM image of Vickers affected zone for GNR-HA nanocomposite, and FESEM image of nanostructure and Vickers crack after sintering for GNR-HA and indentation. As the curves show, the contact depth for pure HA is greater than that for GNR-HA sample. In other words, more force is needed to achieve a constant contact depth in GNR-HA. According to these diagrams, the elastic work in pure HA is greater than the GNR-HA sample. Additionally, the plastics work is slightly higher in pure HA, but with a smaller ratio, which is obtained from the surface below the curves. In these diagrams, the transition to the left means the improvement of mechanical properties. The indentation analysis results show that the hardness, and the Young's modulus of GNR-HA sample, are higher than that of pure HA. Figure 5d,e shows the FESEM images of cracks formed during mechanical analysis on sintered samples. GNRs have increased the samples fracture toughness with GNRs pull-out and GNRs bridging mechanisms. The GNR's pull out energy is much higher than the energy needed to pull out of HA from each other, because GNRs have a higher specific surface area [40,41]. 


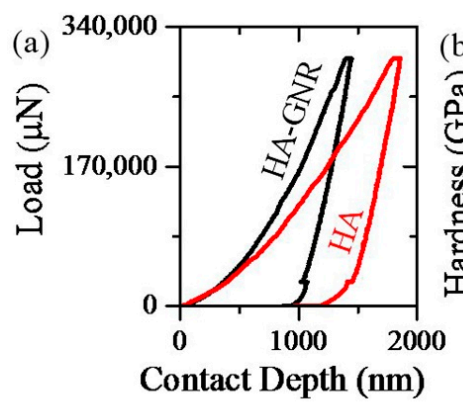

(d)

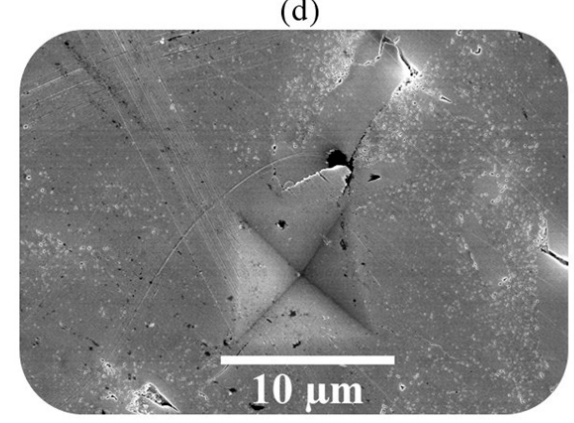

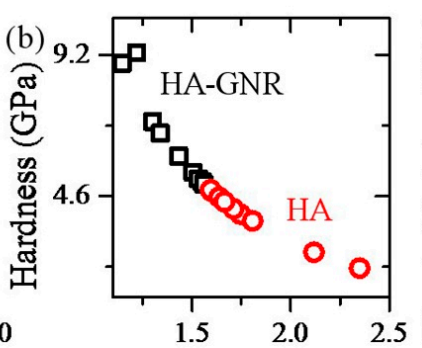

Contact Depth $(\mu \mathrm{m})$

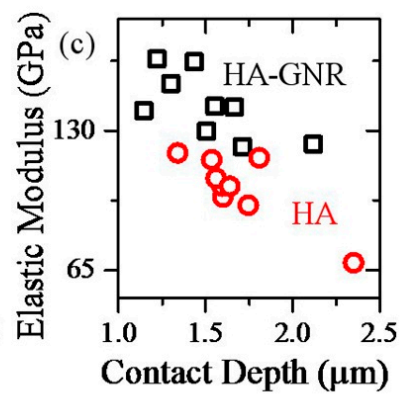

(e)

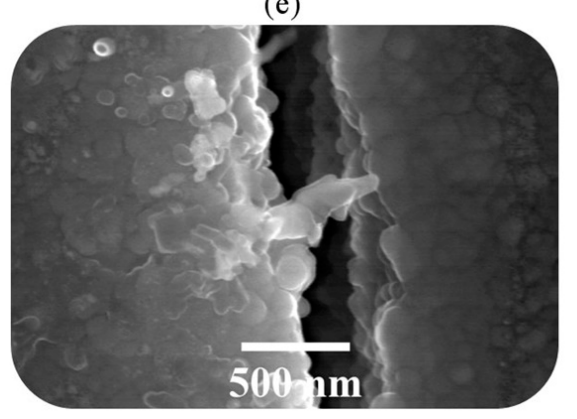

Figure 5. (a) Load-contact depth diagram, (b) hardness-contact depth diagram, (c) elastic moduluscontact depth diagram, (d) FESEM image of Vickers affected zone for GNR-HA nanocomposite, and (e) FESEM image of nanostructure and Vickers crack after sintering for GNR-HA and indentation.

Figure 6 shows the statistical analysis of elastic modulus and hardness for GNR-HA nanocomposite and pure HA. This analysis shows how the mechanical behaviors of HA change with the addition of small amounts of GNRs.

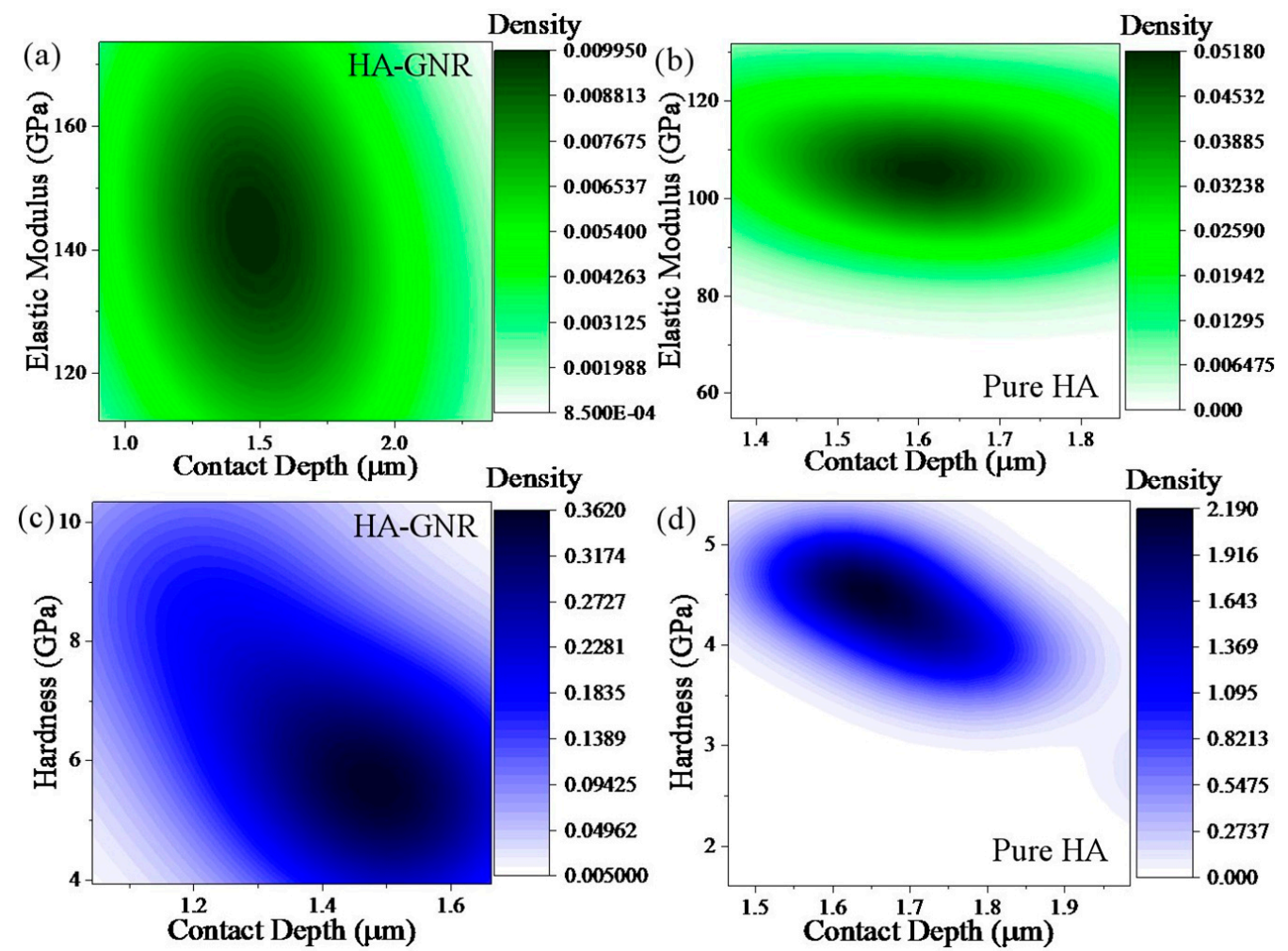

Figure 6. Statistical analysis of $(\mathbf{a}, \mathbf{b})$ elastic modulus and $(\mathbf{c}, \mathbf{d})$ hardness for GNR-HA nanocomposite and pure HA. 
Figure 7 shows fluorescent cell culture images on composite sample after $72 \mathrm{~h}$ and results of the MTT (colorimetric assay for assessing cell metabolic activity) assay. It can be concluded that the leached obtained showed no significant toxicity to the osteoblasts culture (over a 7-day period). The only difference with the previously published work [52] is the morphology of the cells that are globular. The presence of GNR, which has become hydrophobic by the loss of its surface agents, may have caused this change.

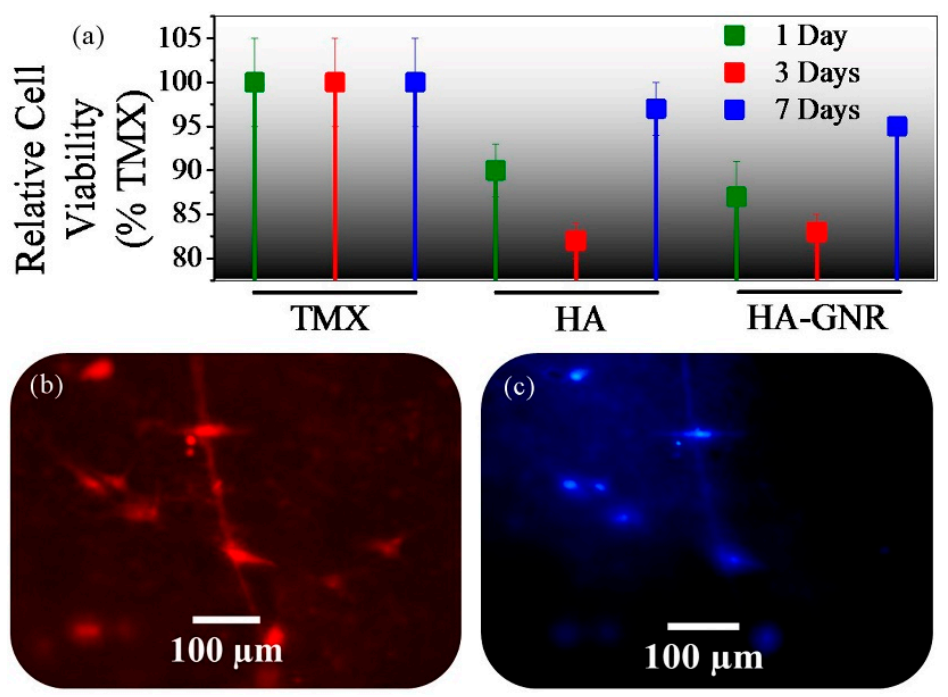

Figure 7. (a) Results of the MTT assay and $(\mathbf{b}, \mathbf{c})$ fluorescent cell culture images on GNR-HA composite after $72 \mathrm{~h}$.

\section{Conclusions}

The findings of this study showed that the final powders synthesized by solvothermal method had a calcium-to-phosphate ratio of about 1.67. In biological experiments, the difference of HA effect in comparison with rGONR-HA was not significant. The results of this study would be appropriate for biomedicine use of this nanocomposite. By adding a small amount of graphene nanoribbon $(0.5 \% \mathrm{~W})$, elastic modulus and hardness of hydroxyapatite increased dramatically. GNRs have increased the samples' fracture toughness with GNR pull-out and GNR bridging mechanisms. According to the HRTEM findings, (300) planes are likely in contact with the surface of GNR. Density calculations from the Archimedes method showed that GNR-HA nanocomposite and pure HA reached to relative densities of $97.11 \%$ and $98.3 \%$, respectively. The results of mechanical analysis showed that in some parts of the nanocomposite, the hardness reached above $9 \mathrm{GPa}$ and the elastic modulus reached above $140 \mathrm{GPa}$.

Author Contributions: Conceptualization, H.N. and R.S.-M.; methodology, R.S.-M.; software, A.H.A.; validation, R.S.-M.; formal analysis, A.H.A.; investigation, H.N.; resources, M.C.P.; data curation, M.C.P.; writing-original draft preparation, H.N.; writing-review and editing, H.N.; supervision, R.S.-M., M.C.P. All authors have read and agreed to the published version of the manuscript.

Funding: This research received no external funding.

Conflicts of Interest: The authors declare no conflict of interest.

\section{References}

1. Li, M.; Xiong, P.; Yan, F.; Li, S.; Ren, C.; Yin, Z.; Li, A.; Li, H.; Ji, X.; Zheng, Y.; et al. An overview of graphene-based hydroxyapatite composites for orthopedic applications. Bioact. Mater. 2018, 3, 1-18. [CrossRef] [PubMed]

2. Gao, C.; Feng, P.; Peng, S.; Shuai, C. Carbon nanotube, graphene and boron nitride nanotube reinforced bioactive ceramics for bone repair. Acta Biomater. 2017, 61, 1-20. [CrossRef] [PubMed] 
3. Ahmadi, A.H.; Nosrati, H.; Sarraf-Mamoory, R. Decreasing $\beta$-three calcium phosphate particle size using graphite as nucleation sites and diethylene glycol as a chemical additive. J. Bioeng. Res. 2019, 1, 50-59.

4. Nosrati, H.; Le, D.Q.S.; Emameh, R.Z.; Bunger, C.E. Characterization of the precipitated Dicalcium Phosphate Dehydrate on the Graphene Oxide surface as a bone cement reinforcement. J. Tissues Mater. 2019, 2, $33-46$.

5. Gholibegloo, E.; Karbasi, A.; Pourhajibagher, M.; Chiniforush, N.; Ramazani, A.; Akbari, T.; Bahador, A.; Khoobi, M. Carnosine-graphene oxide conjugates decorated with hydroxyapatite as promising nanocarrier for ICG loading with enhanced antibacterial effects in photodynamic therapy against Streptococcus mutans. J. Photochem. Photobiol. B: Boil. 2018, 181, 14-22. [CrossRef]

6. Iafisco, M.; Di Foggia, M.; Bonora, S.; Prat, M.; Roveri, N. Adsorption and spectroscopic characterization of lactoferrin on hydroxyapatite nanocrystals. Dalton Trans. 2011, 40, 820-827. [CrossRef]

7. Tavafoghi, M.; Brodusch, N.; Gauvin, R.; Cerruti, M. Hydroxyapatite formation on graphene oxide modified with amino acids: Arginine versus glutamic acid. J. R. Soc. Interface 2016, 13, 20150986. [CrossRef]

8. Zhang, R.; Metoki, N.; Sharabani-Yosef, O.; Zhu, H.; Eliaz, N. Hydroxyapatite/Mesoporous Graphene/Single-Walled Carbon Nanotubes Freestanding Flexible Hybrid Membranes for Regenerative Medicine. Adv. Funct. Mater. 2016, 26, 7965-7974. [CrossRef]

9. Nosrati, H.; Sarraf-Mamoory, R.; Le, D.Q.S.; Bünger, C.E. Enhanced fracture toughness of three dimensional graphene-hydroxyapatite nanocomposites by employing the Taguchi method. Compos. B Eng. 2020, 190, 107928. [CrossRef]

10. Moldovan, M.; Prodan, D.; Sarosi, C.; Carpa, R.; Socaci, C.; Rosu, M.-C.; Pruneanu, S.M. Synthesis, morpho-structural properties and antibacterial effect of silicate-based composites containing graphene oxide/hydroxyapatite. Mater. Chem. Phys. 2018, 217, 48-53. [CrossRef]

11. Canillas, M.; Rivero, R.; García-Carrodeguas, R.; Barba, F.; Rivas-Mercury, J.; Garcia-Carrodeguas, R.; Rodriguez, M.A. Processing of hydroxyapatite obtained by combustion synthesis. Boletín de la Sociedad Española de Cerámica y Vidrio 2017, 56, 237-242. [CrossRef]

12. Guo, X.; Yan, H.; Zhao, S.; Li, Z.; Li, Y.; Liang, X. Effect of calcining temperature on particle size of hydroxyapatite synthesized by solid-state reaction at room temperature. Adv. Powder Technol. 2013, 24, 1034-1038. [CrossRef]

13. Shirkhanzadeh, M. Direct formation of nanophase hydroxyapatite on cathodically polarized electrodes. J. Mater. Sci. Mater. Electron. 1998, 9, 67-72. [CrossRef] [PubMed]

14. Jillavenkatesa, A.; Sr, R.A.C. Sol-gel processing of hydroxyapatite. J. Mater. Sci. 1998, 33, 4111-4119. [CrossRef]

15. Kuriakose, T.; Kalkura, S.N.; Palanichamy, M.; Arivuoli, D.; Dierks, K.; Bocelli, G.; Betzel, C. Synthesis of stoichiometric nano crystalline hydroxyapatite by ethanol-based sol-gel technique at low temperature. J. Cryst. Growth 2004, 263, 517-523. [CrossRef]

16. Sinitsyna, O.V.; Veresov, A.G.; Kovaleva, E.S.; Kolen'Ko, Y.V.; Putlyaev, V.I.; Tretyakov, Y.D. Synthesis of hydroxyapatite by hydrolysis of $\alpha-\mathrm{Ca}_{3}\left(\mathrm{PO}_{4}\right)_{2}$. Russ. Chem. Bull. 2005, 54, 79-86. [CrossRef]

17. Liu, C.; Huang, Y.; Shen, W.; Cui, J. Kinetics of hydroxyapatite precipitation at pH 10 to 11. Biomaterials 2001, 22, 301-306. [CrossRef]

18. Manuel, C.M.; Ferraz, M.P.; Monteiro, F.J. Synthesis of hydroxyapatite and tri calcium phosphate nanoparticles Preliminary Studies. Key Eng. Mater. 2003, 240-242, 555-558. [CrossRef]

19. Yamashita, K.; Arashi, T.; Kitagaki, K.; Yamada, S.; Umegaki, T.; Ogawa, K. Preparation of Apatite Thin Films through rf-Sputtering from Calcium Phosphate Glasses. J. Am. Ceram. Soc. 1994, 77, 2401-2407. [CrossRef]

20. Kimura, I. Synthesis of Hydroxyapatite by Interfacial Reaction in a Multiple Emulsion. Res. Lett. Mater. Sci. 2007, 2007, 1-4. [CrossRef]

21. Tas, A.C. Synthesis of biomimetic Ca-hydroxyapatite powders at $37^{\circ} \mathrm{C}$ in synthetic body fluids. Biomaterials 2000, 21, 1429-1438. [PubMed]

22. Qi, C.; Zhu, Y.-J.; Ding, G.-J.; Wu, J.; Chen, F. Solvothermal synthesis of hydroxyapatite nanostructures with various morphologies using adenosine $5^{\prime}$-monophosphate sodium salt as an organic phosphorus source. RSC Adv. 2015, 5, 3792-3798. [CrossRef]

23. Neira, I.S.; Kolen’Ko, Y.V.; Lebedev, O.I.; Van Tendeloo, G.; Gupta, H.S.; Guitián, F.; Yoshimura, M. An Effective Morphology Control of Hydroxyapatite Crystals via Hydrothermal Synthesis. Cryst. Growth Des. 2009, 9, 466-474. [CrossRef] 
24. Peng, F.; Yu, X.; Wei, M. In vitro cell performance on hydroxyapatite particles/poly(l-lactic acid) nanofibrous scaffolds with an excellent particle along nanofiber orientation. Acta Biomater. 2011, 7, 2585-2592. [CrossRef] [PubMed]

25. Jevtić, M.; Mitrić, M.; Škapin, S.; Jančar, B.; Ignjatović, N.L.; Uskoković, D.P. Crystal Structure of Hydroxyapatite Nanorods Synthesized by Sonochemical Homogeneous Precipitation. Cryst. Growth Des. 2008, 8, 2217-2222.

26. Costa, D.O.; Dixon, S.J.; Rizkalla, A. One- and Three-Dimensional Growth of Hydroxyapatite Nanowires during Sol-Gel-Hydrothermal Synthesis. ACS Appl. Mater. Interfaces 2012, 4, 1490-1499. [CrossRef]

27. Zhang, Y.; Lu, J.; Wang, J.; Yang, S.; Chen, Y. Synthesis of nanorod and needle-like hydroxyapatite crystal and role of pH adjustment. J. Cryst. Growth 2009, 311, 4740-4746. [CrossRef]

28. Chandanshive, B.B.; Rai, P.; Rossi, A.; Ersen, O.; Khushalani, D. Synthesis of hydroxyapatite nanotubes for biomedical applications. Mater. Sci. Eng. C 2013, 33, 2981-2986.

29. Sun, Q.; Lou, J.-T.; Kang, F.; Chen, J.-F.; Wang, J.-X. Facile preparation of hydroxyapatite nanotubes assisted by needle-like calcium carbonate. Powder Technol. 2014, 261, 49-54. [CrossRef]

30. Medeiros, J.S.; Oliveira, A.M.; De Carvalho, J.O.; Ricci, R.; Martins, M.D.C.C.; Rodrigues, B.V.M.; Webster, T.J.; Viana, B.C.; De Vasconcellos, L.M.R.; Canevari, R.A.; et al. Nanohydroxyapatite/Graphene Nanoribbons Nanocomposites Induce in Vitro Osteogenesis and Promote in Vivo Bone Neoformation. ACS Biomater. Sci. Eng. 2018, 4, 1580-1590. [CrossRef]

31. Li, H.; Song, X.; Li, B.; Kang, J.; Liang, C.; Wang, H.; Yu, Z.; Qiao, Z. Carbon nanotube-reinforced mesoporous hydroxyapatite composites with excellent mechanical and biological properties for bone replacement material application. Mater. Sci. Eng. C 2017, 77, 1078-1087.

32. Abden, M.; Afroze, J.; Alam, M.; Bahadur, N. Pressureless sintering and mechanical properties of hydroxyapatite/functionalized multi-walled carbon nanotube composite. Mater. Sci. Eng. C 2016, 67, 418-424.

33. Qu, Y.; He, F.; Yu, C.; Liang, X.; Liang, N.; Ma, L.; Zhang, Q.; Lv, J.; Wu, J. Advances on graphene-based nanomaterials for biomedical applications. Mater. Sci. Eng. C 2018, 90, 764-780.

34. Nie, C.; Ma, L.; Li, S.; Fan, X.; Yang, Y.; Cheng, C.; Zhao, W.; Zhao, C. Recent progresses in graphene based biofunctional nanostructures for advanced biological and cellular interfaces. Nano Today 2019, 26, 57-97. [CrossRef]

35. Gadipelli, S.; Guo, Z.X.; Srinivas, G. Graphene-based materials: Synthesis and gas sorption, storage and separation. Prog. Mater. Sci. 2015, 69, 1-60. [CrossRef]

36. Bai, R.G.; Ninan, N.; Muthoosamy, K.; Manickam, S. Graphene: A versatile platform for nanotheranostics and tissue engineering. Prog. Mater. Sci. 2018, 91, 24-69.

37. Shin, S.R.; Li, Y.-C.; Jang, H.L.; Khoshakhlagh, P.; Akbari, M.; Nasajpour, A.; Zhang, Y.S.; Tamayol, A.; Khademhosseini, A. Graphene-based materials for tissue engineering. Adv. Drug Deliv. Rev. 2016, 105, 255-274. [CrossRef]

38. Stoller, M.D.; Park, S.; Zhu, Y.; An, J.; Ruoff, R.S. Graphene-Based Ultracapacitors. Nano Lett. 2008, 8, 3498-3502. [CrossRef]

39. Wang, S.; Zhang, S.; Wang, Y.; Sun, X.; Sun, K. Reduced graphene oxide/carbon nanotubes reinforced calcium phosphate cement. Ceram. Int. 2017, 43, 13083-13088. [CrossRef]

40. Baradaran, S.; Moghaddam, E.; Basirun, W.; Mehrali, M.; Sookhakian, M.; Hamdi, M.; Moghaddam, M.N.; Alias, Y. Mechanical properties and biomedical applications of a nanotube hydroxyapatite-reduced graphene oxide composite. Carbon 2014, 69, 32-45. [CrossRef]

41. Nosrati, H.; Mamoory, R.S.; Le, D.Q.S.; Bünger, C.E. Preparation of reduced graphene oxide/hydroxyapatite nanocomposite and evaluation of graphene sheets/hydroxyapatite interface. Diam. Relat. Mater. 2019, 100, 107561. [CrossRef]

42. Meng, X.; Cui, X.; Rager, M.; Zhang, S.; Wang, Z.; Yu, J.; Harn, Y.W.; Kang, Z.; Wagner, B.K.; Liu, Y.; et al. Cascade charge transfer enabled by incorporating edge-enriched graphene nanoribbons for mesostructured perovskite solar cells with enhanced performance. Nano Energy 2018, 52, 123-133. [CrossRef]

43. Nosrati, H.; Mamoory, R.S.; Dabir, F.; Le, D.Q.S.; Bünger, C.E.; Perez, M.C.; Rivas-Mercury, J. Effects of hydrothermal pressure on in situ synthesis of 3D graphene- hydroxyapatite nano structured powders. Ceram. Int. 2019, 45, 1761-1769. [CrossRef] 
44. Nosrati, H.; Mamoory, R.S.; Dabir, F.; Perez, M.C.; Rivas-Mercury, J.; Le, D.Q.S.; Bünger, C.E. In situ synthesis of three dimensional graphene-hydroxyapatite nano powders via hydrothermal process. Mater. Chem. Phys. 2019, 222, 251-255. [CrossRef]

45. Nikolaev, A.; Gopin, A.; Severin, A.V.; Rudin, V.; Mironov, M.; Dezhkunov, N. Ultrasonic synthesis of hydroxyapatite in non-cavitation and cavitation modes. Ultrason. Sonochem. 2018, 44, 390-397. [CrossRef]

46. Turon, P.; Del Valle, L.J.; Alemán, C.; Puiggali, J. Biodegradable and Biocompatible Systems Based on Hydroxyapatite Nanoparticles. Appl. Sci. 2017, 7, 60. [CrossRef]

47. Chen, M.H.; Yoshioka, T.; Ikoma, T.; Hanagata, N.; Lin, F.H.; Tanaka, J. Photoluminescence and doping mechanism of theranostic $\mathrm{Eu}^{3+} / \mathrm{Fe}^{3+}$ dual-doped hydroxyapatite nanoparticles. Sci. Technol. Adv. Mater. 2014, 15, 055005. [CrossRef]

48. Cipreste, M.F.; De Rezende, M.R.; Hneda, M.; Peres, A.M.; Cotta, A.A.C.; Teixeira, V.; Macedo, W.A.D.A.; De Sousa, E.M.B. Functionalized-radiolabeled hydroxyapatite/tenorite nanoparticles as theranostic agents for osteosarcoma. Ceram. Int. 2018, 44, 17800-17811. [CrossRef]

49. Roy, S.; Jaiswal, A. Graphene-Based Nanomaterials for Theranostic Applications. Rep. Adv. Phys. Sci. 2017, 1, 1750011. [CrossRef]

50. Liu, Z.; Liang, X.-J. Nano-Carbons as Theranostics. Theranostics 2012, 2, 235-237. [CrossRef]

51. Orecchioni, M.; Cabizza, R.; Bianco, A.; Delogu, L.G. Graphene as Cancer Theranostic Tool: Progress and Future Challenges. Theranostics 2015, 5, 710-723. [CrossRef] [PubMed]

52. Nosrati, H.; Mamoory, R.S.; Le, D.Q.S.; Bünger, C.E.; Emameh, R.Z.; Dabir, F. Gas injection approach for synthesis of hydroxyapatite nanorods via hydrothermal method. Mater. Charact. 2020, 159, 110071. [CrossRef]

53. Oliver, W.; Pharr, G. An improved technique for determining hardness and elastic modulus using load and displacement sensing indentation experiments. J. Mater. Res. 1992, 7, 1564-1583. [CrossRef]

54. Zhang, B.; Chen, G.; Guo, Q. Static Frame Model Validation with Small Samples Solution Using Improved Kernel Density Estimation and Confidence Level Method. Chin. J. Aeronaut. 2012, 25, 879-886. [CrossRef]

55. O'Brien, T.; Kashinath, K.; Cavanaugh, N.; Collins, W.; O'Brien, J.P. A fast and objective multidimensional kernel density estimation method: FastKDE. Comput. Stat. Data Anal. 2016, 101, 148-160. [CrossRef]

56. Wijesinghe, W.; Mantilaka, M.M.M.G.P.G.; Premalal, E.; Herath, H.; Mahalingam, S.; Edirisinghe, M.; Rajapakse, R. Facile synthesis of both needle-like and spherical hydroxyapatite nanoparticles: Effect of synthetic temperature and calcination on morphology, crystallite size and crystallinity. Mater. Sci. Eng. C 2014, 42, 83-90.

57. Kaygili, O.; Keser, S.; Bulut, N.; Ates, T. Characterization of Mg-containing hydroxyapatites synthesized by combustion method. Phys. B Condens. Matter 2018, 537, 63-67. [CrossRef]

58. Saleh, T.A. The influence of treatment temperature on the acidity of MWCNT oxidized by HNO3 or a mixture of $\mathrm{HNO}_{3} / \mathrm{H}_{2} \mathrm{SO}_{4}$. Appl. Surface Sci. 2011, 257, 7746-7751. [CrossRef]

59. Saleh, T.A. Nanocomposite of carbon nanotubes/silica nanoparticles and their use for adsorption of $\mathrm{Pb}(\mathrm{II})$ : From surface properties to sorption mechanism. Desalination Water Treat. 2015, 57, 1-15. [CrossRef]

60. Fadillah, G.; Saleh, T.A.; Wahyuningsih, S.; Putri, E.N.K.; Febrianastuti, S. Electrochemical removal of methylene blue using alginate-modified graphene adsorbents. Chem. Eng. J. 2019, 378, 122140. [CrossRef]

61. Saleh, T.A.; Fadillah, G. Recent trends in the design of chemical sensors based on graphene-metal oxide nanocomposites for the analysis of toxic species and biomolecules. TrAC Trends Anal. Chem. 2019, 120, 115660. [CrossRef]

62. Saleh, T.A. Simultaneous adsorptive desulfurization of diesel fuel over bimetallic nanoparticles loaded on activated carbon. J. Clean. Prod. 2018, 172, 2123-2132. [CrossRef]

63. Nosrati, H.; Sarraf-Mamoory, R.; Dabir, F. Crystallographic study of hydrothermal synthesis of hydroxyapatite nano-rods using Brushite precursors. J. Tissues Mater. 2019, 2, 1-8.

64. Nosrati, H.; Mamoory, R.S.; Le, D.Q.S.; Bünger, C.E. Fabrication of gelatin/hydroxyapatite/3D-graphene scaffolds by a hydrogel 3D-printing method. Mater. Chem. Phys. 2020, 239, 122305. [CrossRef]

(C) 2020 by the authors. Licensee MDPI, Basel, Switzerland. This article is an open access article distributed under the terms and conditions of the Creative Commons Attribution (CC BY) license (http://creativecommons.org/licenses/by/4.0/). 